\begin{tabular}{|c|c|}
\hline Title & Negative ion species in atmospheric-pressure helium dc glow discharge produced in ambient air \\
\hline Author(s) & Sasaki, Koichi; Hosoda, Ryohei; Shirai, Naoki \\
\hline Citation & $\begin{array}{l}\text { Plasma Sources Science and Technology, 29(8), } 085012 \\
\text { https://doi .org/10.1088/1361-6595/aba6a3 }\end{array}$ \\
\hline Issue Date & $2020-08$ \\
\hline Doc URL & http:/hdl.handle.net/2115/82317 \\
\hline Rights & $\begin{array}{l}\text { This is the A ccepted Manuscript version of an article accepted for publication in Plasma Sources Science and } \\
\text { Technology. IOP Publishing } L \text { td is not responsible for any errors or omissions in this version of the manuscript or any } \\
\text { version derived from it. The V ersion of Record is available online at https://doi.org/10.1088/1361-6595/aba6a3 }\end{array}$ \\
\hline Rights(URL) & https://creativecommons.org/icenses/by-nc-nd/4.0/ \\
\hline Tyре & article (author version) \\
\hline File Information & Negative_ion_Atmospheric_rev_clean.pdf \\
\hline
\end{tabular}

Instructions for use 


\title{
Negative ion species in atmospheric-pressure helium dc glow discharge produced in ambient air
}

\author{
Koichi Sasaki, Ryohei Hosoda, and Naoki Shirai \\ Division of Applied Quantum Science and Engineering, Hokkaido University, Kita 13, \\ Nishi 8, Kita-ku, Sapporo 060-8628, Japan \\ E-mail: sasaki@qe.eng.hokudai.ac.jp
}

\begin{abstract}
Experimental investigation on negative ions in atmospheric-pressure plasmas is insufficient to date. In this work, we examined negative ion species in atmospheric-pressure helium dc glow discharge produced in ambient air by laser photodetachment spectroscopy, where the pulsed increase in the discharge current was measured as a function of the laser wavelength. A major negative ion species was $\mathrm{O}^{-}$which was originated from molecular oxygen in the ambient air. $\mathrm{OH}^{-}$and $\mathrm{Cl}^{-}$ were also major negative ion species when we used an $\mathrm{NaCl}$ solution as the cathode of the dc discharge. $\mathrm{O}_{2}^{-}$was minor in comparison with $\mathrm{O}^{-}$, and $\mathrm{H}^{-}$was negligible. The production process of $\mathrm{OH}^{-}$was not dissociative electron attachment to $\mathrm{H}_{2} \mathrm{O}$. The experimental results are consistent with the dominant production of $\mathrm{OH}^{-}$due to dissociative electron attachment to $\mathrm{H}_{2} \mathrm{O}_{2}$.
\end{abstract}

Submitted to: Plasma Sources Sci. Technol.

\section{Introduction}

Recently, atmospheric-pressure plasmas attract much attention, because they have opened new applications of plasmas in medicine [1-3] and agriculture [4-6]. The plasma sources developed with the intention of applying them to medicine and agriculture are usually operated in ambient air [7-10]. Noble gases such as helium and argon are widely used for producing atmospheric-pressure plasmas, but the plasmas usually contain oxygen and nitrogen which are admixed from the ambient air to the noble gas flow. In addition, the admixture of water vapor is not negligible in many atmosphericpressure plasmas, especially in the cases that the plasmas interact with water-containing objects such as biological tissues. Water vapor is the ingredient of $\mathrm{OH}$ [11] which is understood to be the most important radical species in medical and agricultural applications as well as in plasma-liquid interaction [12].

Oxygen and water vapor are electronegative gases. It is well known that plasmas produced with electronegative gases contain negative ions. Low-pressure plasmas with negative ions were investigated intensively in conjunction with the development of dry 
etching technology more than twenty years ago $[13,14]$. It has been understood by a numerical simulation that the transport and the confinement of charged particles in electronegative plasmas are different from those in electropositive plasmas [15]. The chemical kinetics and the spatial structures of atmospheric-pressure plasmas with negative ions have been investigated by many authors using numerical modeling [16-21]. In contrast, experimental investigations of negative ions in atmospheric-pressure plasmas are seriously insufficient to date. The influence of negative ions to the propagation of ionization waves is discussed in some experimental works [21,22], but the negative ion density has not been measured in atmospheric-pressure plasmas.

A reason for the small number of experimental investigations on negative ions in atmospheric-pressure plasmas is the difficulty in the diagnostics. A widely used method for detecting negative ions in electronegative low-pressure plasmas is laser photodetachment combined with Langmuir probes $[23,24]$. However, the Langmuir probe does not work in atmospheric-pressure plasma due to the high collision frequency inside the sheath around the probe tip. An alternative method is laser absorption spectroscopy [25], where laser photons are lost during the propagation in the electronegative plasma by the photodetachment reaction with negative ions. This method needs the combination with cavity ringdown spectroscopy (CRDS) because of the small absorption coefficient due to photodetachment [26, 27]. However, the CRSD measurement may be problematic in atmospheric-pressure plasmas with sizes in the millimeter range, since the light refraction at the curved boundary between the plasma and the ambient gas influences the optical alignment of the cavity [28]. According to these reasons, the experimental investigations of the detection of negative ions in atmospheric-pressure plasmas exclusively employ mass spectrometry [29-31]. However, mass spectrometry may have difficulty in the extraction of negative ions, since placing the sampling orifice is the significant disturbance to atmospheric-pressure plasmas with small sizes [32]. The potential difference between the plasma and the sampling orifice is another problem in the extraction of negative ions.

In this work, we adopted laser photodetachment to atmospheric-pressure helium de glow discharge produced in ambient air. This type of discharge is specific for the detection of negative ions by laser photodetachment, since the production of electrons from negative ions changes the electric conductivity of the plasma, resulting in the pulsed change in the discharge current. Tschiersch and coworkers have applied laser photodetachment to the investigation of the pre-ionization stage of dielectric barrier discharges, and they also detected the electrical response of the discharge circuit to laser photodetachment $[33,34]$. In this work, we examined the negative ion species in the plasma from the relationship between the photodetachment current and the laser wavelength. 


\section{Experiment}

Figure 1 shows the plasma source and the electrical circuit used in the experiment. The plasma was produced by applying a dc high voltage between a planar electrode and a stainless-steel nozzle electrode which had inner and outer diameters of 0.5 and 0.8 $\mathrm{mm}$, respectively. The nozzle electrode was connected to the positive side of a dc power supply via a $50 \mathrm{k} \Omega$ resistor. The planar electrode was connected to the negative side of the dc power supply via a $50 \Omega$ register, which was used for measuring the current through the circuit from the voltage drop. The negative side of the dc power supply was electrically grounded. The planar electrode was a stainless-steel plate or the surface of $\mathrm{NaCl}$ solution. The distance between the tip of the anode and the planar cathode was $4 \mathrm{~mm}$. The voltage between the anode and the cathode was dependent on the cathode material, and it was 900-1000 V when the discharge current was $20 \mathrm{~mA}$. Helium flowed from the stainless-steel nozzle electrode at a flow rate of $400 \mathrm{sccm}$. In some experiments, the helium flow was surrounded by the flow of sheath gas which was provided by placing another gas nozzle around the stainless-steel nozzle electrode. We injected the pulsed laser beam yielded from a tunable dye laser or an optical parametric oscillator into the plasma from the radial direction. The duration of the laser pulse was approximately 8 ns. The laser energy was dependent on the wavelength, since we used the second harmonic generation of the dye laser, the fundamental oscillation of the dye laser, and the idler oscillation of the optical parametric oscillator for the ultraviolet, visible, and infrared wavelengths, respectively. The laser beam was not focused, and almost the entire region of the plasma was illuminated by the laser beam. We were careful in avoiding the ablation of the electrodes, since the ablation caused a serious electrical noise at the timing of the pulsed laser injection.

\section{Results and discussion}

\subsection{Temporal variation of discharge current}

The temporal variation of the discharge current at the timing of the pulsed laser injection is shown in Fig. 2. The origin of the horizontal axis corresponds to the timing of the Q-switching of the Nd:YAG laser which was used for the optical pumping of the dye laser. The cathode was the stainless-steel plate. In this measurement, the dc discharge current (20 mA in this example) and its pulsed temporal variation were observed using the dc and ac coupling modes of the oscilloscope, respectively. A higher sensitivity was adopted at the ac coupling mode. Figure 2 shows the waveform recorded at the ac coupling mode, and the dc current before the laser pulse injection is labeled by referring the signal recorded at the dc coupling mode. The wavelength and the energy of the dye laser beam were $682.6 \mathrm{~nm}$ and $40 \mathrm{~mJ}$, respectively. The laser wavelength was measured using a wave meter with the accuracy of $\pm 5 \mathrm{pm}$. As shown in the figure, we observed the pulsed increase in the discharge current at the timing of the pulsed laser injection. The duration of the pulsed current was approximately $100 \mathrm{~ns}$. The amplitude of the pulsed 
current was dependent on the ambient gas species. The highest and lowest amplitudes were observed when the helium flow was surrounded by oxygen and nitrogen sheath gases, respectively. The amplitude of the pulsed current was medium when we applied no sheath gases.

The pulsed increase in the discharge current is considered to be due to the production of electrons from negative ions in the plasma (laser photodetachment, $\left.\mathrm{X}^{-}+h \nu \rightarrow \mathrm{X}+\mathrm{e}\right)$. The production of electrons from negative ions do not change the total amount of negative charges in the plasma. However, since the mobility of electrons is much higher than negative ions, we can expect the increase in the current passing through the plasma. The influence of the ambient gas species on the amplitude of the pulsed current is consistent with the speculation of laser photodetachment, since oxygen and nitrogen are electronegative and electropositive gases, respectively. Another possibility for the mechanism of the pulsed current is photoionization of neutral species [35]. However, the contribution of photoionization may not be dominant, since the amplitude of the pulsed current is sensitive to the laser wavelength and it is small at a longer wavelength than the photodetachment threshold (Figs. 4 and 5).

\subsection{Amplitude of pulsed current}

We repeated the measurement of the pulsed current shown in Fig. 2 at various laser energies. Figure 3 shows the ratio between the amplitude of the pulsed current $\left(I_{\mathrm{pd}}\right)$ and the dc discharge current $\left(I_{0}\right)$ as a function of the laser energy. The same plasma produced in the ambient air at a discharge current of $20 \mathrm{~mA}$ was illuminated by laser pulses with various energies. The experimental results are represented by the plots, while the solid curve shows the theoretical prediction on the photodetachment ratio [23],

$$
\alpha=\frac{\Delta n_{-}}{n_{-}}=1-\exp \left(-\frac{\sigma \lambda E_{\mathrm{L}}}{h c S}\right),
$$

where $\Delta n_{-} / n_{-}$shows the ratio of photodetached negative ion density to the total negative ion density, $\sigma$ is the cross section of photodetachment, $c$ is the speed of light, $h$ is the Plank constant, and $\lambda, E_{\mathrm{L}}$, and $S$ are the wavelength, the energy, and the cross section of the laser beam, respectively. It is noted that $\Delta n_{-}$corresponds to the density of electrons produced from negative ions by laser photodetachment. As shown in the figure, we observed the agreement between $I_{\mathrm{pd}} / I_{0}$ and the theoretical prediction of

$\Delta n_{-} / n_{-}$. Therefore, we can conclude that the photodetachment current $I_{\mathrm{pd}}$ represents the relative value of the negative ion density in the plasma.

\subsection{Detection of $\mathrm{O}^{-}$}

Since photodetachment has the threshold for the photon energy, we can obtain the knowledge of the negative ion species if we carry out the photodetachment experiment at various laser wavelengths. Figure 4 shows the photodetachment current as a function of the laser wavelength between 835 and $860 \mathrm{~nm}$. The infrared laser beam was obtained 
by the idler oscillation of the optical parametric oscillator. The laser energy was approximately $12 \mathrm{~mJ}$. The cathode was the $\mathrm{NaCl}$ solution with a concentration of $1 \%$. The plasma was produced in the ambient air at a discharge current of $20 \mathrm{~mA}$. As shown in the figure, we observed the decrease in the photodetachment current with the laser wavelength. The photodetachment ratio of $\mathrm{O}^{-}$is shown by blue plots in Fig. 4, which was obtained by substituting the laser parameters and the photodetachment cross section of $\mathrm{O}^{-}[36]$ into eq. (1). As shown in the figure, the variation of the photodetachment current coincided with the photodetachment ratio predicted on the basis of the cross section data. Therefore, the experimental result shown in Fig. 4 gives us the evidence that $\mathrm{O}^{-}$is a negative ion species in the plasma. Since the photodetachment cross section is negligible at $860 \mathrm{~nm}$ for $\mathrm{O}^{-}$, the photodetachment current observed at $860 \mathrm{~nm}$ is due to negative ion species which have the photodetachment threshold at a longer wavelength than $860 \mathrm{~nm}$. The possibilities are $\mathrm{O}_{2}^{-}$and $\mathrm{H}^{-}$in the experimental condition, but $\mathrm{O}_{2}^{-}$is more likely as will be described below. Figure 4 indicates that the density of $\mathrm{O}^{-}$is higher than that of $\mathrm{O}_{2}^{-}$, which is consistent with the speculation reported by Nemschokmichal and coworkers [34].

The influence of the sheath $\mathrm{O}_{2}$ gas is shown in Fig. 5. As shown in the figure, we observed the significant increase in the photodetachment current of $\mathrm{O}^{-}$when the helium flow was surrounded by the sheath $\mathrm{O}_{2}$ gas. This result suggests the production of $\mathrm{O}^{-}$by dissociative electron attachment to $\mathrm{O}_{2}\left(\mathrm{O}_{2}+\mathrm{e} \rightarrow \mathrm{O}^{-}+\mathrm{O}\right)$. In addition, as shown in Fig. 5, we observed the increase in the photodetachment current at $860 \mathrm{~nm}$. The source of $\mathrm{H}^{-}$in this experimental condition is water vapor in the ambient gas. It is reasonably considered that the sheath $\mathrm{O}_{2}$ gas reduces the water vapor density in the ambient gas. Hence, if the negative ion species photodetached at $860 \mathrm{~nm}$ is $\mathrm{H}^{-}$, we may observe the decrease in the photodetachment current when the helium flow is surrounded by the sheath $\mathrm{O}_{2}$ gas. However, the experimental result is opposite as shown in Fig. 5, indicating that the negative ion species photodetached at $860 \mathrm{~nm}$ is $\mathrm{O}_{2}^{-}$which is produced by three-body electron attachment $\mathrm{O}_{2}+\mathrm{e}+\mathrm{M} \rightarrow \mathrm{O}_{2}^{-}+\mathrm{M}$.

\subsection{Detection of $\mathrm{OH}^{-}$}

Figure 6 shows the photodetachment current as a function of the laser wavelength between 670 and $710 \mathrm{~nm}$. The energy of the laser pulse yielded from the dye laser was 47 $\mathrm{mJ}$. The plasma was produced in the ambient air at a discharge current of $20 \mathrm{~mA}$ using the stainless-steel plate as the cathode. The photodetachment ratio expected from the

photodetachment cross section of $\mathrm{OH}^{-}[37,38]$ is also shown in Fig. 6. The variation of the photodetachment current agreed well with the photodetachment ratio, as shown in the figure. Therefore, the experimental result shown in Fig. 6 is the evidence that $\mathrm{OH}^{-}$ is a negative ion species in the plasma. The photodetachment current observed at 700 $\mathrm{nm}$ is due to $\mathrm{O}^{-}$and $\mathrm{O}_{2}^{-}$. The ratio of the photodetachment current due to $\mathrm{OH}^{-}$to that due to $\mathrm{O}^{-}$and $\mathrm{O}_{2}^{-}$is small, as shown in Fig. 6, indicating that $\mathrm{OH}^{-}$is minor in the negative ion composition in the plasma produced using the stainless-steel plate as 
the cathode.

When the cathode was the $\mathrm{NaCl}$ solution with a concentration of $1 \%$, we observed the photodetachment current shown in Fig. 7. The photodetachment current using the stainless-steel cathode (the same data as those shown in Fig. 6) is also plotted in Fig 7 for comparison. As shown in the figure, we observed the significant increase in the photodetachment current due to $\mathrm{OH}^{-}$by using the $\mathrm{NaCl}$ solution as the cathode. In addition, we observed the increase in the photodetachment current at a wavelength of $700 \mathrm{~nm}$. As will be described below, this increase is caused by the increase in the $\mathrm{O}^{-}$ density in the plasma.

\subsection{Production process of $\mathrm{OH}^{-}$}

The enhancement of the photodetachment current or the increase in the $\mathrm{OH}^{-}$density by using the liquid cathode is related with the increase in the water vapor density in the ambient air. However, considering the cross section data [39,40], dissociative electron attachment to $\mathrm{H}_{2} \mathrm{O}$ is not the production process of $\mathrm{OH}^{-}$. The cross section of dissociative electron attachment to $\mathrm{H}_{2} \mathrm{O}$ to produce $\mathrm{H}^{-}$is on the order of $10^{-18}$ $\mathrm{cm}^{2}$ and its threshold energy is approximately $5.5 \mathrm{eV}$. In addition, the cross section to produce $\mathrm{O}^{-}$is on the order of $10^{-19} \mathrm{~cm}^{2}$ and its threshold energy is approximately 4.5 $\mathrm{eV}$. The cross section to produce $\mathrm{OH}^{-}$is on the order of $10^{-20} \mathrm{~cm}^{2}$ and its threshold energy is approximately $4.3 \mathrm{eV}$ [39]. According to the experimental result shown in Fig. 7, the enhancement of the photodetachment current by using the liquid cathode was more remarkable for $\mathrm{OH}^{-}$than $\mathrm{O}^{-}$, which cannot be explained by the smaller cross section of dissociative electron attachment to produce $\mathrm{OH}^{-}$than $\mathrm{O}^{-}$. In addition, the increase in the photodetachment current at $860 \mathrm{~nm}$ was not remarkable by using the liquid cathode, suggesting that the increase in the $\mathrm{H}^{-}$density is not significant when we used the $\mathrm{NaCl}$ solution as the cathode. This also contradicts the fact that dissociative electron attachment to $\mathrm{H}_{2} \mathrm{O}$ has the largest cross section for the production of $\mathrm{H}^{-}$.

We believe that the major production process of $\mathrm{OH}^{-}$in the plasma produced in the ambient humid air is dissociative electron attachment to $\mathrm{H}_{2} \mathrm{O}_{2}$. The production process of $\mathrm{H}_{2} \mathrm{O}_{2}$ may be three-body reaction $\mathrm{OH}+\mathrm{OH}+\mathrm{M} \rightarrow \mathrm{H}_{2} \mathrm{O}_{2}+\mathrm{M}$. We have shown that $\mathrm{OH}$ radicals are available in the liquid cathode discharge [41]. The cross section of dissociative electron attachment to $\mathrm{H}_{2} \mathrm{O}_{2}$ is on the order of $10^{-17} \mathrm{~cm}^{2}$ [42]. The cross section for the production of $\mathrm{OH}^{-}$has a larger cross section than that for $\mathrm{O}^{-}$, and the ratio is approximately four. Therefore, the remarkable increase in the $\mathrm{OH}^{-}$ density, the moderate increase in the $\mathrm{O}^{-}$density, and the negligible increase in the $\mathrm{H}^{-}$ density, which were observed by using the liquid cathode, are explained reasonably by assuming dissociative electron attachment to $\mathrm{H}_{2} \mathrm{O}_{2}$. In addition, the cross section of dissociative electron attachment to $\mathrm{H}_{2} \mathrm{O}_{2}$ is large at a low electron energy (the peak is located around $0.5 \mathrm{eV}$ ) [42]. Since the electron temperature of the atmospheric-pressure dc glow discharge, which was measured by laser Thomson scattering, is $2 \mathrm{eV}[43,44]$, dissociative electron attachment to $\mathrm{H}_{2} \mathrm{O}_{2}$ can have a much larger rate coefficient than 
that to $\mathrm{H}_{2} \mathrm{O}$ with the threshold energy higher than $4.3 \mathrm{eV}$.

\subsection{Detection of $\mathrm{Cl}^{-}$}

Finally, we examined the existence of $\mathrm{Cl}^{-}$in the plasma when we used the $\mathrm{NaCl}$ solution with a concentration of $1 \%$ as the cathode. Figure 8 shows the photodetachment current as a function of the laser wavelength between 340 and $348 \mathrm{~nm}$. The ultraviolet laser beam was obtained by the second harmonic generation of the dye laser. The laser energy was $13 \mathrm{~mJ}$. The photodetachment ratio expected from the photodetachment cross section of $\mathrm{Cl}^{-}[45,46]$ is also shown in Fig. 8. Just three plots in Fig. 8 for the photodetachment ratio is due to the limited number of the cross section data in the wavelength range. The agreement between the photodetachment current and the photodetachment ratio indicates the existence of $\mathrm{Cl}^{-}$in the plasma. The photodetachment ratio at 340 $\mathrm{nm}$ is estimated to be 0.5 , as shown in Fig. 8, since this wavelength is close to the photodetachment threshold of $\mathrm{Cl}^{-}$. This means that we expect a two times higher photodetachment current if we can detach electrons from all $\mathrm{Cl}^{-}$negative ions. Therefore, it is speculated that $\mathrm{Cl}^{-}$is a major negative ion species in the plasma. It has been reported that the optical emission of $\mathrm{Na}$ is observed in the atmospheric-pressure de glow discharge when the $\mathrm{NaCl}$ solution is used as the cathode $[47,48]$. However, the optical emission of $\mathrm{Cl}$ is never observed in the same plasma, suggesting that the $\mathrm{Cl}$ density is considerably low. The reason for the low $\mathrm{Cl}$ density has not been clarified yet, but the present experimental result shows that a part of $\mathrm{Cl}$ is converted to $\mathrm{Cl}^{-}$in the plasma. The production process of $\mathrm{Cl}^{-}$has not been understood yet. Since we may need molecular species with $\mathrm{Cl}$ to produce $\mathrm{Cl}^{-}$by dissociative electron attachment, the first step to understand the production process of $\mathrm{Cl}^{-}$is the detection of $\mathrm{Cl}_{2}$ and $\mathrm{NaCl}$ in the plasma.

\subsection{Possibility of other negative ion species}

We did not examine other negative ion species such as $\mathrm{O}_{3}^{-}, \mathrm{O}_{4}^{-}, \mathrm{O}^{-}\left(\mathrm{H}_{2} \mathrm{O}\right)$, and $\mathrm{O}_{2}^{-}\left(\mathrm{H}_{2} \mathrm{O}\right)_{n}$, which are considered in numerical simulation $[17,20]$. The $\mathrm{O}_{4}^{-}$density increases with the $\mathrm{O}_{2}$ density, and it can be a major negative ion species when the $\mathrm{O}_{2}$ concentration is $\sim 10 \%$ [17]. Hence, it is expected that $\mathrm{O}_{4}^{-}$is negligible in the heliumbased discharge used in the experiment. The $\mathrm{O}_{3}^{-}$density is significantly affected by the $\mathrm{O}_{3}$ density $[17,20]$. It has been reported that the $\mathrm{O}_{3}$ density in a de discharge is much lower than that in a dielectric barrier discharge [49]. In addition, the gas temperature in the helium de glow discharge is as high as $2500 \mathrm{~K}$ [41], which is a harmful condition for the effective production of $\mathrm{O}_{3}$. Therefore, we presume that the densities of $\mathrm{O}_{3}^{-}$and $\mathrm{O}_{3}$ are low in the helium de glow discharge. We also presume that $\mathrm{O}^{-}\left(\mathrm{H}_{2} \mathrm{O}\right)$ and $\mathrm{O}_{2}^{-}\left(\mathrm{H}_{2} \mathrm{O}\right)_{n}$ cannot survive in the active discharge plasma with the high gas temperature. 


\section{Conclusions}

In this work, we examined negative ion species in atmospheric-pressure helium dc glow discharge produced in ambient air by laser photodetachment spectroscopy. It has been shown that the dominant negative ion species is $\mathrm{O}^{-}$which is originated from molecular oxygen in the ambient air. $\mathrm{O}_{2}^{-}$is a minority in comparison with $\mathrm{O}^{-}$, and $\mathrm{H}^{-}$is negligible. $\mathrm{Cl}^{-}$is a major negative ion species when we used a $\mathrm{NaCl}$ solution as the cathode of the dc discharge. $\mathrm{OH}^{-}$is another major negative ion species in the liquid cathode discharge. The production process of $\mathrm{OH}^{-}$is not dissociative electron attachment to $\mathrm{H}_{2} \mathrm{O}$. The experimental results are consistent with the dominant production of $\mathrm{OH}^{-}$due to dissociative electron attachment to $\mathrm{H}_{2} \mathrm{O}_{2}$.

\section{Acknowledgments}

The authors would like to thank Fumiyoshi Tochikubo for useful discussion.

\section{References}

[1] Fridman G, Friedman G, Gutsol A, Shekhter A B, Vasilets V N, and Fridman A 2008 Plasma Process. Polym. 5503

[2] Kong M G, Kroesen G, Morfill G, Nosenko T, Shimizu T, van Dijk J, and Zimmermann J L 2009 New J. Phys. 11115012

[3] Weltmann K-D, Polak M, Masur K, von Woedtke T, Winter J, and Reuter S 2012 Contrib. Plasma Phys. 52644

[4] Perni S, Liu D W, Shama G, and Kong M G, 2008 J. Food Prot. 71302

[5] Šerá B, Gajdová I, Šerý M, and Špatenka P, 2013 Plasma Sci. Technol. 15935

[6] Thirumdasa R, Kothakotab A, Annapurec U, Siliverud K, Blundelle R, Gattf R, and Valdramidisg V P 2018 Trends Food Sci. Technol. 7721

[7] Bekeschus S, Schmidt A, Weltmann K-D, and von Woedtke T 2016 Clinical Plasma Medicine 4 19

[8] Yamada H, Shimizu T, Fujiwara M, Kato S, Fujiwara Y, Itagaki H, Kiyama S, Kim J, Ikehara S, Shimizu N, Nakanishi H, Ikehara Y, and Sakakita H 2018 Plasma Sources Sci. Technol. 27 05LT02

[9] Golda J, Held J, Redeker B, Konkowski M, Beijer P, Sobota A, Kroesen G, Braithwaite N St J, Reuter S, Turner M M, Gans T, O'Connell D, and Schulz-von der Gathen V 2016 J. Phys. D: Appl. Phys. 49084003

[10] Iseki S, Hashizume H, Jia F, Takeda K, Ishikawa K, Ohta T, Ito M, and Hori M 2011 Appl. Phys. Express 4116201

[11] Bruggeman P and Schram D C 2010 Plasma Sources Sci. Technol. 19045025

[12] Bruggeman P J, Kushner M J, Locke B R, Gardeniers J G E, Graham W G, Graves D B, HofmanCaris R C H M, Maric D, Reid J P, Ceriani E, Rivas D F, Foster J E, Garrick S C, Gorbanev Y, Hamaguchi S, Iza F, Jablonowski H, Klimova E, Kolb J, Krcma F, Lukes P, Machala Z, Marinov I, Mariotti D, Thagard S M, Minakata D, Neyts E C, Pawlat J, Petrovic Z L, Pflieger R, Reuter S, Schram D C, Schröer S, Shiraiwa M, Tarabo'a B, Tsai P A, Verlet J R, von Woedtke T, Wilson K R, Yasui K, and Zvereva G 2016 Plasma Sources Sci. Technol. 25053002

[13] Samukawa S and Mieno T 1996 Plasma Sources Sci. Technol. 5132

[14] Ahn T H, Nakamura K, and Sugai H 1996 Plasma Sources Sci. Technol. 5139

[15] Nakano N, Shimura N, Petrović Z L, and Makabe M 1994 Phys. Rev. E 494455 
[16] Stalder K R, Vidmar R J, Nersisyan G, and Graham W G 2006 J. Appl. Phys. 99093301.

[17] Liu D-X, Rong M-Z, Wang X-H, Iza F, Kong M G, and Bruggeman P 2010 Plasma Process. Polym. 7846

[18] Yang A J, Wang X H, Rong M Z, Liu D X, Iza F, and Kong M G 2011 Phys. Plasmas 18113503

[19] Kelly S and Turner M M 2014 Plasma Sources Sci. Technol. 23065013

[20] Lietz A M and Kushner M J 2016 J. Phys. D: Appl. Phys. 49425204

[21] Schmidt-Bleker A, Norberg S A, Winte J, Johnsen E, Reuter S, Weltmann K D, and Kushner M J 2015 Plasma Sources Sci. Technol. 24035022

[22] Razavizadeh S, Ghomi H, and Sobota A 2018 Plasma Sources Sci. Technol. 27075016

[23] Bacal M, Hamilton G W, Bruneteau A M, and Doucet J 1979 Rev. Sci. Instrum. 50719

[24] Takada N, Hayashi D, Sasaki K, and Kadota K 1997 Jpn. J. Appl. Phys. 36 L1702

[25] Quandt E, Döbele H F, and Graham W G 1998 Appl. Phys. Lett. 722394

[26] Quandt E, Kraemer I, and Döbele H F 1999 Europhys. Lett. 4532

[27] Mimo A, Nakano H, Wimmer, Wunderlich D, Fantz U, and Tsumori K 2020 Rev. Sci. Instrum. 9101351

[28] Zaima K, Tomioka S, and Sasaki K 2015 Jpn. J. Appl. Phys. 54088005

[29] Bruggeman P, Iza F, Lauwers D, and Gonzalvo Y A 2010 J. Phys. D: Appl. Phys. 43012003

[30] Oh J-S, Gonzalvo Y A, and Bradley J W 2011 J. Phys. D: Appl. Phys. 44365202

[31] McKay K, Walsh J L, and Bradley J W 2013 Plasma Sources Sci. Technol. 22035005

[32] Große-Kreul S, Hübner S, Schneider S, Ellerweg D, von Keudell A, Matejčík S, and Benedikt J 2015 Plasma Sources Sci. Technol. 24044008

[33] Tschiersch R, Nemschokmichal S, and Meichsner J 2017 Plasma Sources Sci. Technol. 26075006

[34] Nemschokmichal S, Tschiersch R, Höft H, Wild R, Bogaczyk M, Becker M M, Loffhagen D, Stollenwerk L, Kettlitz M, Brandenburg R, and Meichsner J 2018 Eur. Phys. J. D 7289

[35] Carbone E A D, Schregel C-G, and Czarnetzki U 2016 Plasma Sources Sci. Technol. 25054004

[36] Génévriez M, Dunseath K M, Terao-Dunseath M, Hibbert A, Dochain A, Marion R, and Urbain X 2018 Phys. Rev. A 98033410

[37] Schulz P A, Mead R D, Jones P L, and Lineberger W C 1982 J. Chem. Phys. 77, 1153

[38] Smith J R, Kim J B, and Lineberger W C 1997 Phys. Rev A 552036

[39] Melton C E 1972 J. Chem. Phys. 574218

[40] Rawat P, Prabhudesai V S, Aravind G, Rahman M A, and Krishnakumar E 2007 J. Phys. B: At. Mol. Opt. Phys. 404625

[41] Ishigame H, Nishiyama S, and Sasaki K 2015 Jpn. J. Appl. Phys. 54 01AF02

[42] Nandi D, Krishnakumar E, Rosa A, Schmidt W-F, and Illenberger E 2003 Chem. Phys. Lett. 373 454

[43] Tomita K, Urabe K, Shirai N, Sato Y, Hassaballa S, Bolouki N, Yoneda M, Shimizu T, and Uchino K 2016 Jpn. J. Appl. Phys. 55066101

[44] Urabe K, Shirai N, Tomita K, Akiyama T, and Murakami T 2016 Plasma Sources Sci. Technol. 25045004

[45] Mandl A 1976 Phys. Rev. A 14345

[46] Radojević V, Kelly H P, and Johnson W R 1987 Phys. Rev. A 352117

[47] Shirai N, Nakazawa M, Ibuka S, and Ishii S 2009 Jpn. J. Appl. Phys. 48036002

[48] Shirai N, Ichinose K, Uchida S, and Tochikubo F 2011 Plasma Sources Sci. Technol. 20034013

[49] Bobkova E S, Smirnov S A, Zalipaeva Y V, and Rybkin V V 2014 Plasma Chem. Plasma Process. 34721 


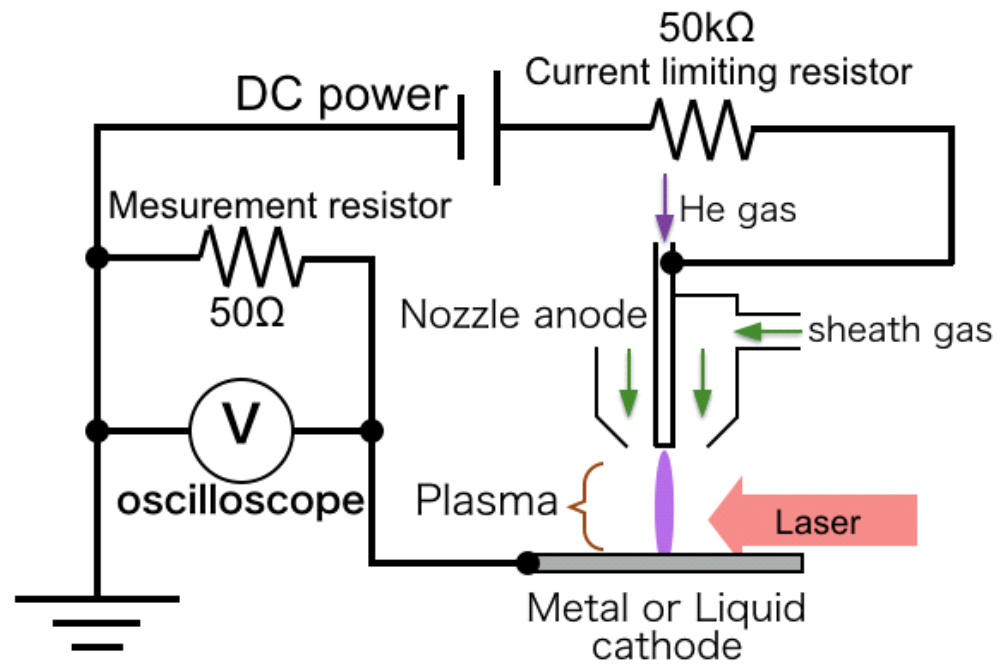

Figure 1. Experimental arrangement. 


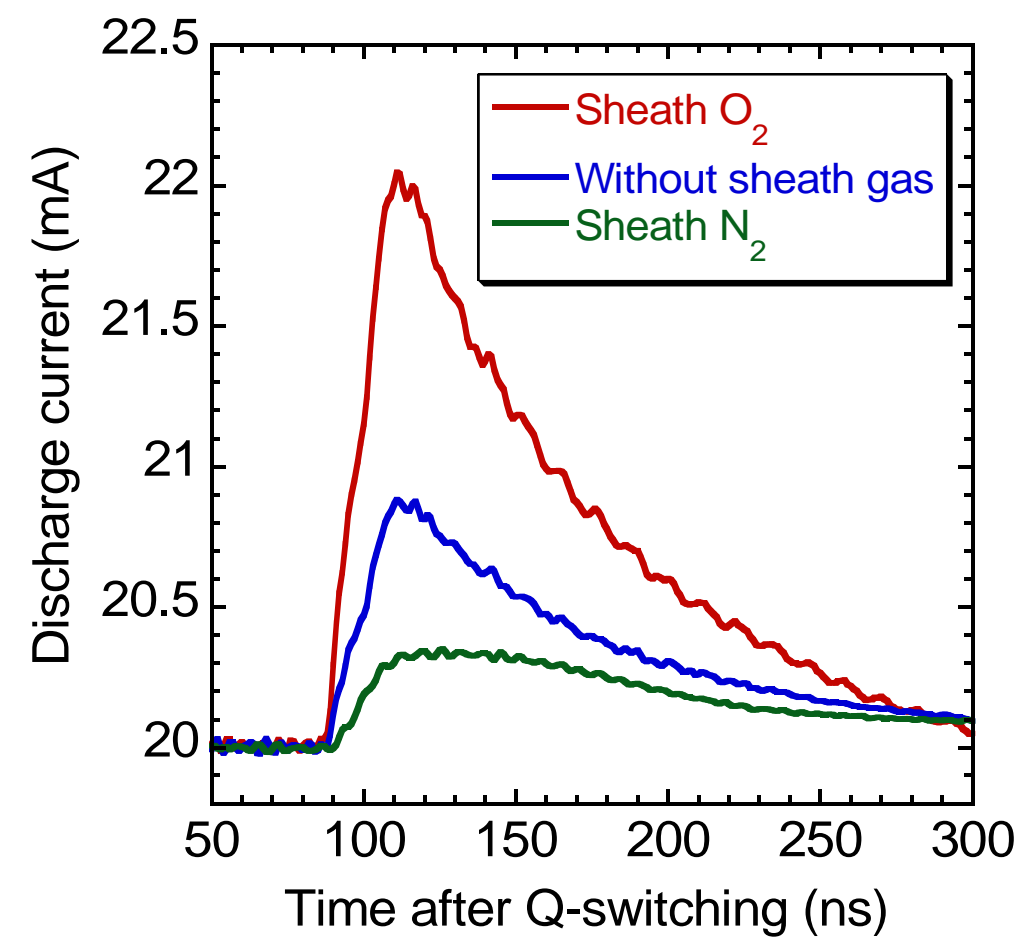

Figure 2. Temporal variation of discharge current at the timing of the pulsed laser injection. Three results observed with three types of ambient gas are shown. 


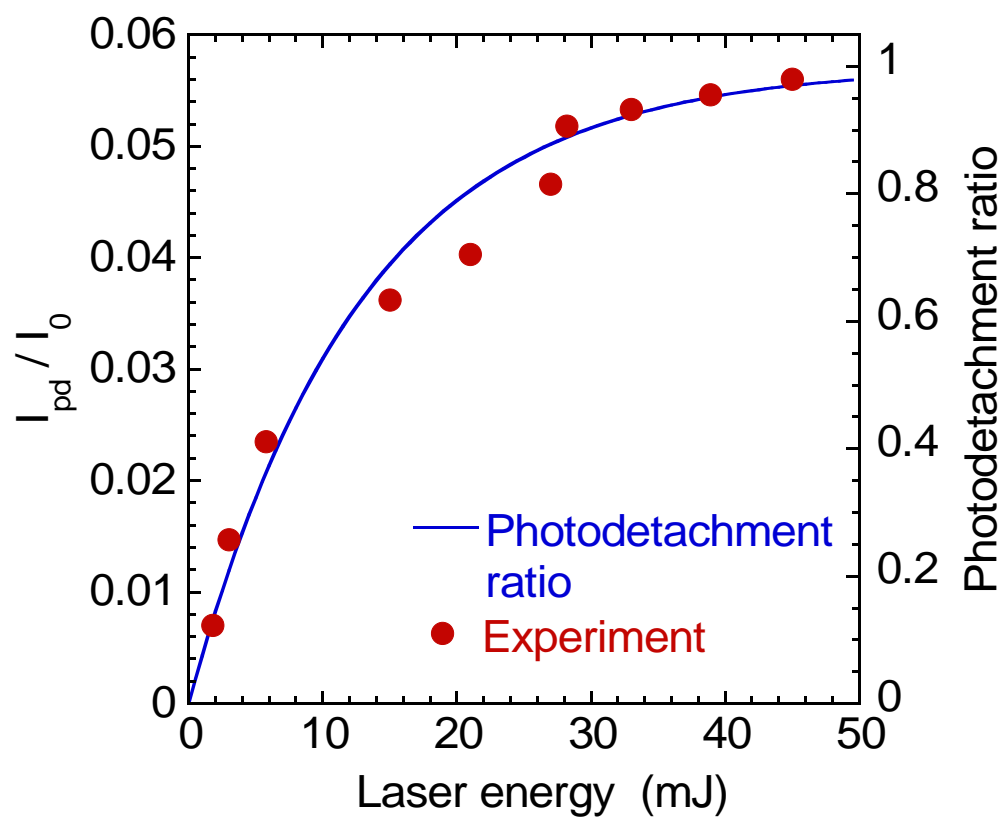

Figure 3. Amplitude of the pulsed increase in the discharge current as a function of the laser energy. The theoretical prediction of the photodetachment ratio is also shown. 


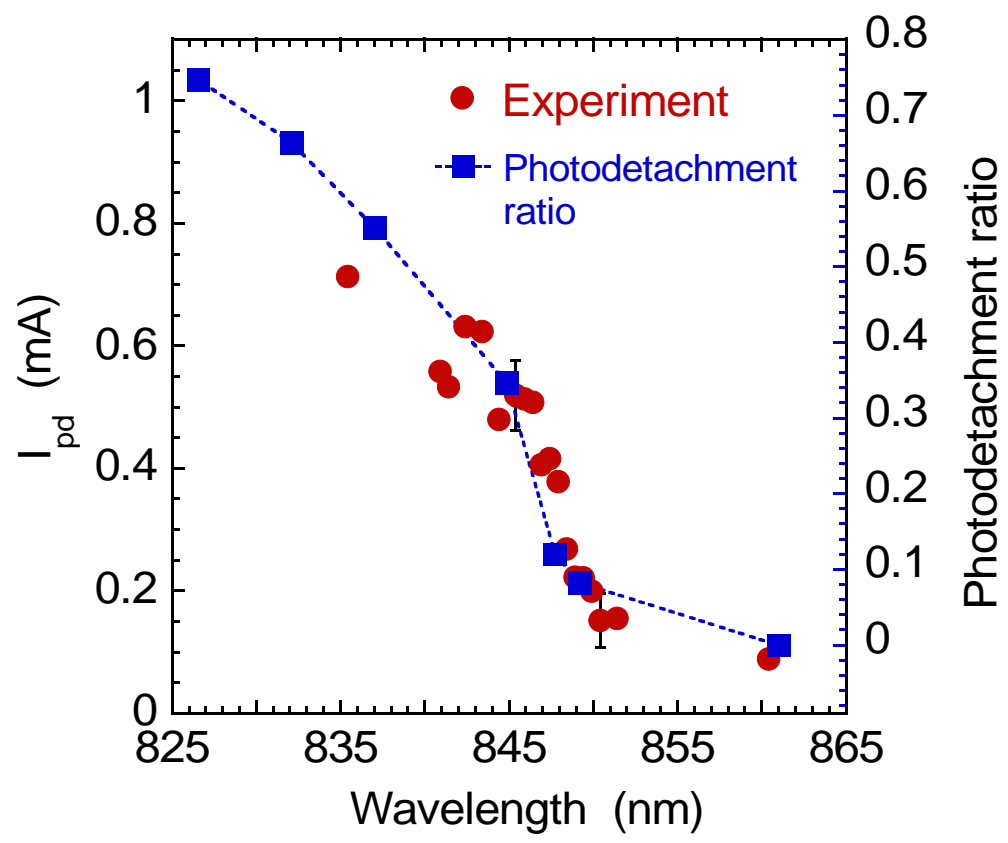

Figure 4. Photodetachment current as a function of the laser wavelength. The photodetachment ratio predicted by the photodetachment cross section of $\mathrm{O}^{-}$is also shown. 


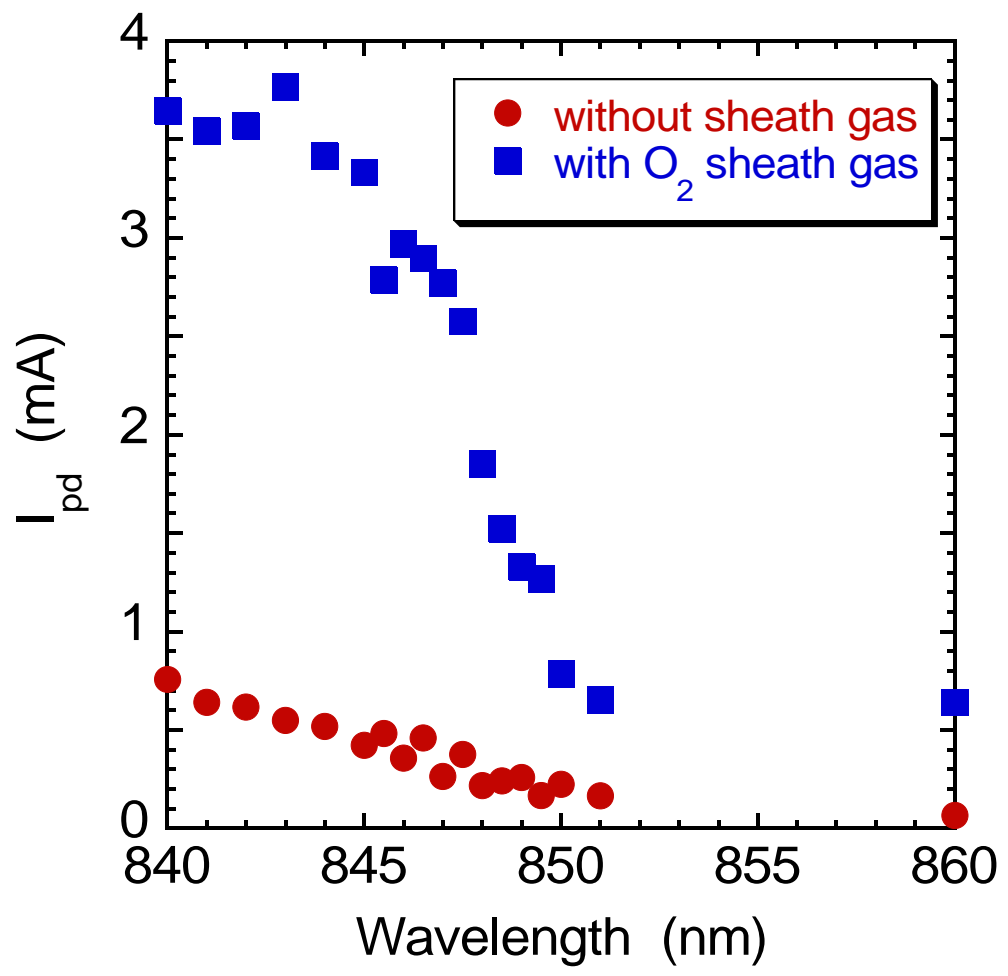

Figure 5. Comparison of the photodetachment current with and without the sheath $\mathrm{O}_{2}$ gas around the He flow. 


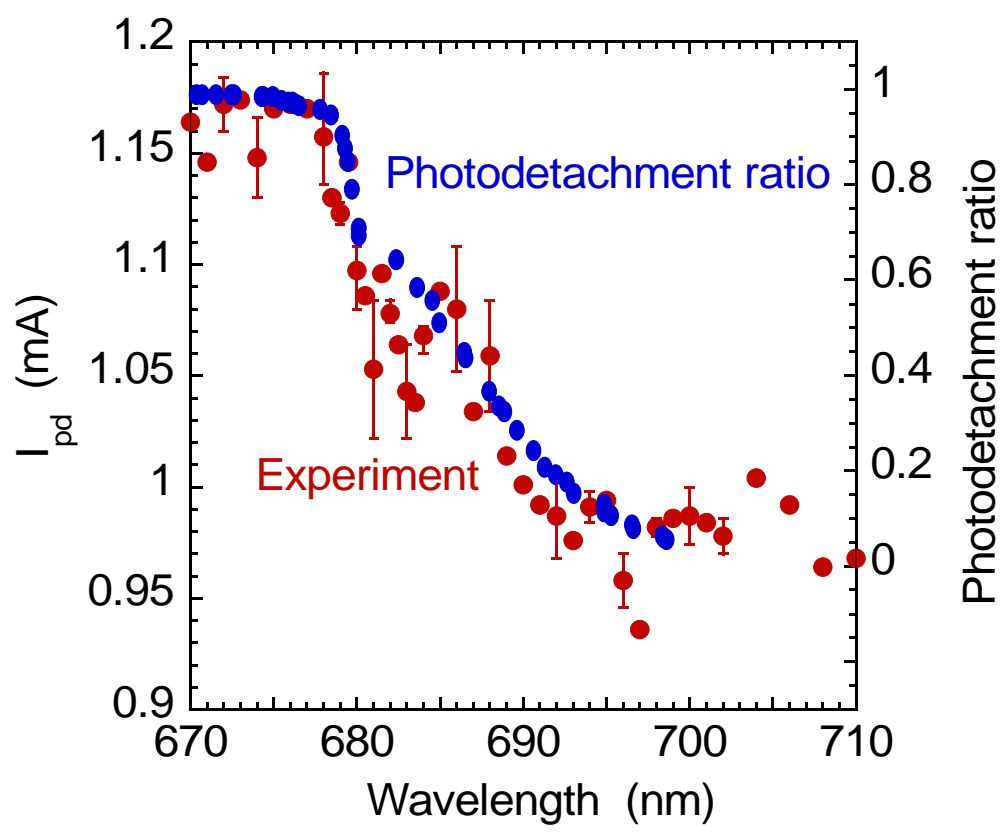

Figure 6. Photodetachment current as a function of the laser wavelength. The cathode was the stainless-steel plate. The photodetachment ratio predicted by the photodetachment cross section of $\mathrm{OH}^{-}$is also shown. 


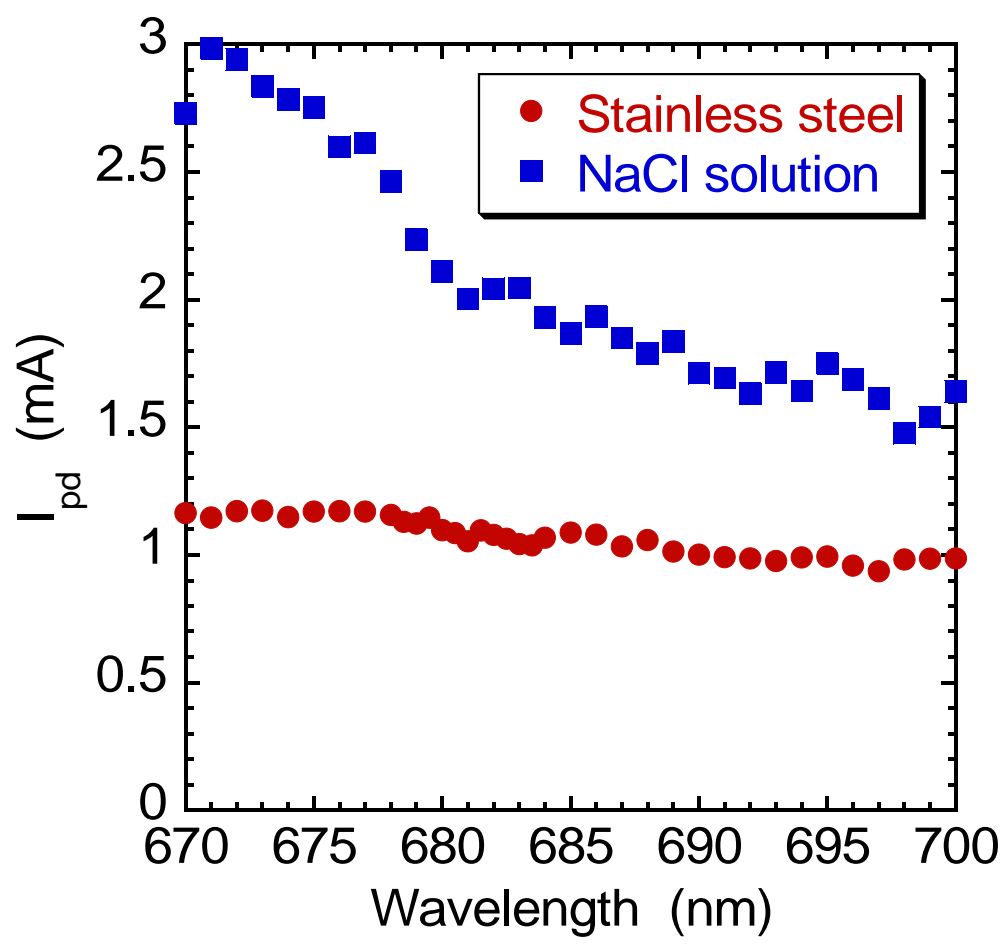

Figure 7. Comparison of the photodetachment current when we used the stainlesssteel plate and the surface of the $\mathrm{NaCl}$ solution as the cathode of the dc discharge. 


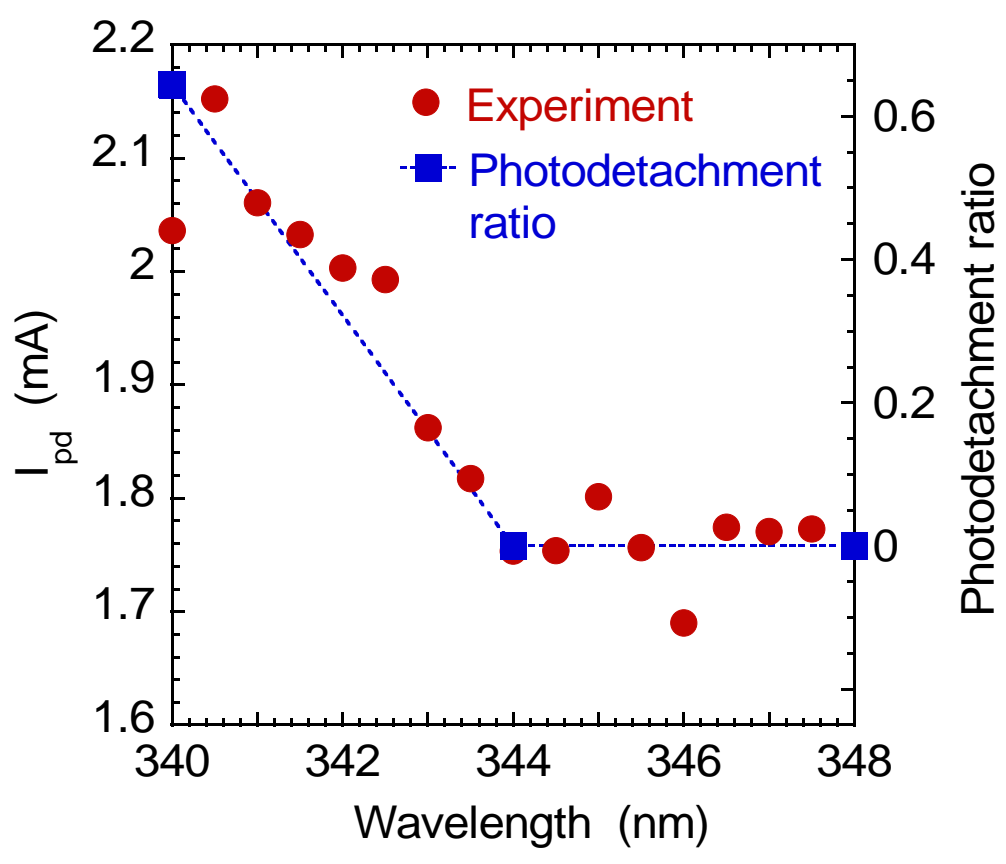

Figure 8. Photodetachment current as a function of the laser wavelength. The cathode was the surface of the $\mathrm{NaCl}$ solution. The photodetachment ratio predicted by the photodetachment cross section of $\mathrm{Cl}^{-}$is also shown. 